\title{
ВНЕДРЕНИЕ ТЕХНОЛОГИЙ КОНТЕКСТНОГО ОБУЧЕНИЯ В ПРОЦЕСС ПРОФЕССИОНАЛЬНОЙ ПОДГОТОВКИ БУДУЩИХ СПЕЦИАЛИСТОВ ГОСТИНИЧНОГО И РЕСТОРАННОГО ДЕЛА
}

\author{
Пицул Е. С., ассистент кафедры туризма, гостиничного и ресторанного дела \\ Луганский наџиональный университет имени Тараса Шевченко, г. Старобельск
}

DOI: https://doi.org/ 10.31435/rsglobal_ws/30092018/6139

\section{ARTICLE INFO}

Received: 23 July 2018

Accepted: 19 September 2018

Published: 30 September 2018

\section{KEYWORDS}

training,

contextual learning,

contextual learning technology

implementation,

professional position of students.

\begin{abstract}
The article refers to the use of contextual learning technology in a university with the aim of forming creative, independently and productively thinking personality. It is proposed that to teach students on the basis of the meaning of the context of their future professional activity, and the training itself to build in connection with the dynamics of the development of the profession, providing a change in meanings, motives, goals, actions, objects and results that act as a means of solving the tasks of a specialist.
\end{abstract}

Citation: Пицул Е. С. (2018) Vnedrenie Tehnologii Kontekstnogo Obucheniya v Process Professionalnoi Podgotovki Buduschih Specialistov Gostinichnogo i Restorannogo Dela. World Science. 9(37). doi: 10.31435/rsglobal_ws/30092018/6139

Copyright: () 2018 Пицул Е. С. This is an open-access article distributed under the terms of the Creative Commons Attribution License (CC BY). The use, distribution or reproduction in other forums is permitted, provided the original author(s) or licensor are credited and that the original publication in this journal is cited, in accordance with accepted academic practice. No use, distribution or reproduction is permitted which does not comply with these terms.

Постановка проблемы. В современных условиях, при традиционной подготовки специалистов гостиничного и ресторанного дела, сформировался целый ряд противоречий, что в свою очередь приводит к таким недостаткам обучения, как отсутствие профессиональной мотивации в будущих специалистах, формальность знаний, неспособность их использования на практике, длительная адаптация молодых специалистов к профессиональной деятельности. Следовательно, можно прийти к выводу, что система образование требует нового подхода, который бы прежде всего отображал специфику будущей профессиональной деятельности студентов.

Одной из возможностей решения данной проблемы является внедрение технологий контекстного обучения, которое предполагает максимальное приближение процесса профессиональной подготовки к реалиям будущей профессиональной деятельности, формирование способности анализировать, прогнозировать и проектировать траектории собственного профессионального роста.

Анализ исследований и публикаций показал, что вопросы внедрения контекстного подхода в процесс профессиональной подготовки будущих специалистов исследовали А. А. Вербицкий, Н.А.Бакшаев, Н. В. Борисова, В. А. Далингер, Т. Д. Дубовицкая, В. М. Кругликов, Н. Б. Лаврентьева, А. Г. Ларионова, Н. Г. Макарченко, Л. А. Машкина, Н. В. Пророк, В.Ф. Тенищев и др. Однако, на наш взгляд, недостаточно исследованы отдельные теоретические вопросы внедрения контекстного обучения в процесс профессиональной подготовки будущих специалистов гостиничного и ресторанного дела.

Изложение основного материала. Основоположником контекстного метода обучения считается А. А. Вербицкий. По мнению ученого, контекстным можно назвать такое обучение, в котором языком науки и с помощью всей системы форм, методов и средств обучения 
(традиционных и новых) последовательно моделируется предметное и социальное содержание будущей профессиональной деятельности студентов [2: 53].

Как отмечает А. А. Вербицкий, при контекстном обучении основным является не передача информации, а развитие способностей студентов компетентно выполнять профессиональные функции, решать профессиональные проблемы и задачи, то есть осваивать целостную профессиональную деятельность. В таких условиях происходит переход деятельности от процесса обучения к формированию навыков выполнения профессиональных обязанностей. Студент осознает, что было (устоявшиеся образцы теории и практики), что есть (выполняемая им познавательная деятельность) и будет (моделируемых ситуации профессиональной деятельности). Все это мотивирует познавательную деятельность, и, как следствие, учебная информация и сам процесс обучения приобретает личностный смысл, информация превращается в личные профессиональные знания студента, а самое главное, что в процессе такого обучения у будущего специалиста формируется устойчивая профессиональная позиция [2: 45].

В акмеологическом словаре профессиональная позиция определяется как система устойчивых отношений работника к себе как к специалисту, своей профессии, труду, обществу, и к другому человеку. Она характеризует профессиональную состоятельность, самооценку, уровень притязаний, отношение к занимаемому статусу в системе общественных процессов в трудовой деятельности. Профессиональная позиция может трансформироваться в ходе профессионализации личности, являясь то результатом, то предпосылкой профессионального совершенствования [1].

Таким образом, можно сделать вывод, что профессиональная позиция выступает основой профессионального становления и развития специалиста, она настраивает личность на профессионально творческую самореализацию и саморазвитие. Именно поэтому в процессе подготовки студентов - будущих специалистов гостиничного и ресторанного дела в системе высшего образования необходимо уделять внимание формированию устойчивой профессиональной позиции обучающихся, начиная с первого курса обучения и до завершения.

На наш взгляд, для того чтобы будущий специалист четко осознавал свою значимость и был мотивирован на дальнейшее обучение, необходимо применять инновационные образовательные технологии, которые помогут не только вооружить будущих специалистов массой теоретических знаний, но и способствуют формированию профессиональных компетенций. Особое внимание следует уделять процессу поэтапного перехода студентов к базовым формам деятельности более высокого уровня: от учебно-познавательной деятельности академического типа к квазипрофессиональной деятельности (сюжетно-ролевые и деловые игры) и, далее к учебно-профессиональной деятельности (научно-исследовательская работа, профильная учебно-производственная практика, стажировка). Преподавание профильных дисциплин необходимо осуществлять в контексте профессиональной деятельности, минимально используя при этом практику академичного изложения научного материала.

Контекст определяется как система внешних и внутренних условий жизни и деятельности человека, влияющая на его восприятие, осознание и преобразование им конкретной ситуации, придавая значение и смысл этой ситуации в целом и отдельным ее компонентам [2].

Внешний контекст представляет собой социокультурные, предметные и пространственновременные характеристики ситуации, в которых личность действует, внутренний - индивидуальнопсихологические особенности, усвоенные знания и опыт человека [2].

Основной замысел авторов технологии контекстного обучения заключается в том, что информация для получения статуса профессионального знания должна восприниматься в контексте собственного практического действия студента. Действие это должно быть не чисто академическим, а приближенным к ситуациям будущей профессиональной деятельности. Условия и содержание профессиональной деятельности всегда вероятностны, проблемны, в этой связи основной единицей профессионального обучения является не отдельная порция теоретического материала или решаемая по образцу задача, а проблемная ситуация, которая предполагает включение творческого мышления студента. Такая система профессиональных ситуаций способствует моделированию и трансформации содержания образования, позволяет интегрировать знания всех изучаемых дисциплин для разрешения предложенной ситуации [5].

Мы разделяем взгляды А. А. Вербицкого, автора технологии контекстного обучения в том, что базисом традиционного обучения является информация - по сути искусственная, знаковая система, характеризующая теоретическую базу профессии, правила и алгоритмы. На основе такого рода информации у студента в процессе профессиональной подготовки в вузе формируется определенный комплекс практических умений и навыков. Вместе с тем, исходя из 
наших наблюдений, производственных практик и стажировок в украинских вузах гораздо меньше, чем теоретической информации. А если теоретическую информацию практически не отработать, такая информация теряет личностный смысл для студента, и основной целью его обучения становится сдача зачетов и экзаменов.

А. А. Вербицкий утверждает, что основные формы организации учебной работы студентов тоже искусственны, так как деятельность специалиста протекает не в форме лекции, семинара или практикума, а в реальной жизни, к которой его не подготавливают в вузе. Поэтому для того, чтобы грамотно работать в реальности, важно пересмотреть традиционную систему обучения будущих специалистов гостинично-ресторанного дела в вузе, используя технологию контекстного обучения ¡4ך.

Данная технология основана на динамическом движении деятельности. Выделяют базовые формы деятельности студентов и различные промежуточные, переходные от одной формы к другой.

К ним относятся: учебная деятельность академического типа, квазипрофессиональная деятельность и учебно-профессиональная деятельность. Рассмотрим их применительно к формированию профессиональной позиции будущих специалистов гостинично-ресторанного дела.

Классическим примером учебной деятельности академического типа является лекция, где имеет место главным образом передача и усвоение теоретического материала. Но, к примеру, на проблемной лекции или семинаре-дискуссии проявляются предметный и социальный контексты будущей профессиональной деятельности. На такой лекции моделируются действия будущих специалистов гостиничного и ресторанного дела, обсуждающие насущные проблемы и вопросы, которые могут возникнуть в ходе реальной профессиональной деятельности.

Квазипрофессиональная деятельность моделируется в аудиторных условиях, например, в деловой игре. Деловые игры являются эффективным методом обучения в условиях подготовки к управлению современным предприятием и предпринимательской деятельности. Учитывая то, что деловые игры моделируют жизненные и производственные ситуации, профессиональные отношения людей, помогают студентам преодолеть неуверенность и способствуют самоутверждению, считаем необходимым использовать их для формирования профессиональной позиции будущего специалиста.

Ролевая игра при подготовке специалистов гостиничного и ресторанного дела, является одним из уникальных методов обучения, помогает студентам решать сложные ситуации, возникающие в реальной профессиональной деятельности. Работая со студентами дневной и заочной формы обучения кафедры туризма, гостиничного и ресторанного дела, мы пришли к выводу, что преподавателю целесообразно переместить акцент на более практические действия по формированию готовности к профессиональной деятельности специалистов в рамках преподавания дисциплин профессионального цикла. Это достигается с помощью расширенного круга вопросов практических задач и конкретных профессиональных реальных ситуаций, которые предоставят студенту понимание о производственных процессах в ресторане или гостинице. На решение именно этих вопросов направлено использование проблемных и игровых методик.

Также важна для будущих специалистов гостиничного и ресторанного дела деятельность, в которой студент выполняет реальные исследовательские или практические функции: научно-исследовательская работа студента, курсовая, дипломная работа, практика (учебная, научно-исследовательская, производственная, преддипломная). Работа студентов, оставаясь учебной, становится по своим целям, формам, содержанию и технологиям профессиональной деятельностью.

Промежуточные формы учебной деятельности обеспечивают поэтапное изменение одной базовой формы деятельности студентов в другую. К ним относятся проблемные лекции, групповые практические занятия, семинары-дискуссии, анализ конкретных ситуаций, возникающих в профессиональной сфере, различные тренинги, спецкурсы и прочее.

Для того чтобы сформировать профессиональную позицию будущего специалиста гостиничного и ресторанного дела, необходимо разрабатывать учебные программы, ориентируясь на изучение теоретических аспектов в тесной связи с практическим. Важно, чтобы задания для семинарских и практических занятий составлялись таким образом, чтобы студент проявил не только навыки владения компьютером и нахождения информации в сети интернет, а был ориентирован на необходимость самостоятельно анализировать, сравнивать, формулировать и делать выводы. Тогда будущий специалист привыкает творчески мыслить, индивидуально подходить к любой ситуации, преодолевать страх столкновения с неразрешимой проблемой. Изучение различных правовых конструкций через деятельностные 
формы обучения формирует уверенное владение навыками и умениями разрешения ситуаций, мотивирует студента к профессиональному саморазвитию.

Таким образом, можно говорить о том, что на текущий момент основным направлением совершенствования системы образования - должна бать концентрация усилий образовательных организаций на внедрение контекстного обучения, а также максимальном вовлечении организаций-работодателей в образовательную деятельность, что в конечном итоге обеспечит сочетание академической подготовки выпускников с получением последними практического опыта и навыков, необходимых для осуществления профессиональной деятельности, а также сократит время адаптации выпускников на предприятиях.

\section{ЛИТЕРАТУРА}

1. Акмеологический словарь / Под ред. А. А. Деркач. М.: РАГС, 2005. 832.

2. Вербицкий А. А. Концепция знаково-контекстного обучения в вузе / А. А. Вербицький / Вопросы психологии. - 1987. - № 5. - С.31-39

3. Вербицкий А. А. Игровые формы контекстного обучения / А. А. Вербицкий. - М.: Знание, 1983. - 234 с.

4. Вербицкий А. А. Компетентностный подход и теория контекстного обучения / А. А. Вербицький. М.: ИЦ ПКПС. - 2004. - 84 с.

5. Жукова И. А. Контекстное обучение как средство формирования профессиональной компетентности будущих юристов: дис. ... канд. пед. наук. М., 2011. 252 с.

6. Левковский М. В. Новые учебные технологии / М.В.Левкивський // Вестник Житомирского государственного университета имени Ивана Франко. - 1999. - № 3. - С. 14 -18.

7. Яворська Ж. Ділові ігри та їх роль у підготовці сучасних фахівців / Ж. Яворська // Вісник Львівського Університету. - 2005. - Вип. 19. - С. 241-246. 